OPEN ACCESS

Edited by:

Alain Charbit,

University Paris Descartes, France

Reviewed by:

Mikhail A. Gavrilin,

Ohio State University, USA

Susu M. Zughaier,

Emory University, USA

${ }^{*}$ Correspondence:

Zheng-Fei Liu

Izf6789@mail.hzau.edu.cn

Received: 17 December 2015

Accepted: 29 February 2016

Published: 15 March 2016

Citation:

Ahmed W, Zheng K and Liu Z-F

(2016) Establishment of Chronic

Infection: Brucella's Stealth Strategy.

Front. Cell. Infect. Microbiol. 6:30

doi: 10.3389/fcimb.2016.00030

\section{Establishment of Chronic Infection: Brucella's Stealth Strategy}

\author{
Waqas Ahmed, Ke Zheng and Zheng-Fei Liu * \\ State Key Laboratory of Agricultural Microbiology, College of Veterinary Medicine, Huazhong Agricultural University, Wuhan, \\ China
}

Brucella is a facultative intracellular pathogen that causes zoonotic infection known as brucellosis which results in abortion and infertility in natural host. Humans, especially in low income countries, can acquire infection by direct contact with infected animal or by consumption of animal products and show high morbidity, severe economic losses and public health problems. However for survival, host cells develop complex immune mechanisms to defeat and battle against attacking pathogens and maintain a balance between host resistance and Brucella virulence. On the other hand as a successful intracellular pathogen, Brucella has evolved multiple strategies to evade immune response mechanisms to establish persistent infection and replication within host. In this review, we mainly summarize the "Stealth" strategies employed by Brucella to modulate innate and the adaptive immune systems, autophagy, apoptosis and possible role of small noncoding RNA in the establishment of chronic infection. The purpose of this review is to give an overview for recent understanding how this pathogen evades immune response mechanisms of host, which will facilitate to understanding the pathogenesis of brucellosis and the development of novel, more effective therapeutic approaches to treat brucellosis.

Keywords: Brucella, "Stealth" strategy, chronic infection, innate immunity, adaptive immunity, autophagy, apoptosis, small noncoding RNA

\section{INTRODUCTION}

Brucella species are the causative agent of brucellosis, among one of major bacterial zoonotic diseases. Brucella is Gram-negative, non-spore-forming, non-motile, facultative anaerobe and intracellular in nature which mainly affect the reproductive tract and cause abortion and infertility in natural host (D'Anastasio et al., 2011). According to host specificity there are 10 species of Brucella: B. melitensis (natural hosts: goat and sheep), B. abortus (natural host: cattle), B. suis (natural host: swine), B. canis (natural host: dogs), B. ovis (natural host: sheep), B. neotomae (natural host: desertmice), B. cetacea (natural host: cetacean), B. pinnipedia (natural host: seal), B. microti (natural host: voles), and B. inopinata (natural host: unknown; Whatmore et al., 2007). However, among recognized Brucella species the most pathogenic for human include B. melitensis, B. abortus, $B$. suis, and B. canis. In addition, Brucella represent public health problems in low income countries (Atluri et al., 2011; Martirosyan et al., 2011). Humans can acquire infection by different ways such as direct contact with diseased animals or by consumption of Brucella affected animal's products. Brucella infection in human is considered as a febrile illness that can progress into a long lasting disease with the appearance of severe complications (de Figueiredo et al., 2015). 
In human and animal brucellosis, persistence occurs in the tissues of mononuclear phagocyte system including bone marrow, lymph nodes, liver and spleen. Additionally, in both human and animal host, Brucella may be encountered within bones and joints, as well as in male reproductive organs while in placenta and fetus of females (Atluri et al., 2011; Martirosyan et al., 2011). If brucellosis is not properly treated, it develops into chronic infection that leads to severe health problems resulting in remarkable morbidity and economic loss in endemic areas (in the Middle East, North, Central and South America, north Africa, Mediterranean countries, and countries of the Caucasus and central Asia; Godfroid et al., 2011). Brucellosis is one of the frequently encountered zoonotic diseases that infect approximately 500,000 new cases annually (Durward et al., 2012). Even though there are some commercial vaccines are used to control animal brucellosis, yet no safe and effective vaccines are available for humans or pregnant animals. Generally, occurrence of human brucellosis is directly linked with natural hosts, and not transmitted from person to person with exception of two reported cases (Pappas et al., 2006).

Due to certain complications, such as economic issues, ethical aspects and practical problems, it is difficult to study brucellosis in natural hosts, as a consequence mice model is widely used to study the relationship of immune response mechanism with brucellosis. The course of murine brucellosis depends upon bacteria (strain, virulence, dose and inoculation route) and certain host parameters including breed, genetic background, age, sex, and physiological status (Grillo et al., 2012). Brucella infection is divided in three steps: in the first step pathogen invades host within 2 days of infection, in second step pathogen replicates within different organs of the reticulo-endothelial and reproductive systems from 2 days to 3 weeks which is known as the acute phase of infection, while in the 3rd step, the pathogen displays differences in the pathology of various tissues and lasts from up to 6 months to 1 year or more, known as chronic phase (Martirosyan et al., 2011; Grillo et al., 2012). During chronic phase, the number of bacteria reaches a maximum level in spleen and liver (from 7 to 12 weeks), followed by the declining chronic phase during which number of bacteria decreases and Brucellae are eliminated from spleen and liver (Martirosyan et al., 2011; Martirosyan and Gorvel, 2013). In this review, we mainly summarize the strategies and mechanisms employed by Brucella to evade the immune response of host as well as implication of these modulations in the pathogenesis of brucellosis.

\section{BRUCELLA PATHOGENESIS}

After internalization, Brucella are challenged with harsh diverse environment situations. The pathogen develops different strategies including evasion and resisting intracellular host defense mechanisms for its adaptation that is predicted by certain structural components or presence of virulence factors. The pathogenesis of brucellosis mainly depends upon macrophages, dendritic cells and placental trophoblasts for its survival and replication (Copin et al., 2012).
There are many intracellular host defense mechanisms, among one of them is degradation within the lysosomal compartments. Brucella control the intracellular trafficking of their vacuoles, named as the Brucella-containing vacuole (BCV) to avoid this degradation (Celli et al., 2003). Fusions of BCVs with membrane elements like endoplasmic reticulum (ER) ultimately favor a safe replicative niche. Internalization of smooth Brucella is facilitated in the macrophage cells by lipid raft attachment to the plasma membrane. EEA-1 and Rab5 are the markers of early endocytic pathway associated with the lipid raft containing vacuole. For the maturation of vacuole, these external lipid rafts high in cholesterol are converted into Brucellae derived $\beta$-1,2-glucans b (von Bargen et al., 2012). Maturation proceeds with the passage of time and early markers present on the BCV are displaced to Rab7 and LAMP-1 subsequently with the interaction to the late endosomal compartments (Figure 1). BCV interact with late endosomes/lysosomes that control vacuolar acidification and transcription of various Brucella factors (for example: virB) but result in inhibition of vacuolar attachment of the proteolytic enzyme, cathepsin D (Boschiroli et al., 2002). The type IV secretion system (T4SS) of Brucella that encodes virB operon thought to be involved in secretion of several putative bacterial factors and support maturation of the BCV ultimately controls the intracellular and stealthy lifestyle of the pathogen (Roux et al., 2007; Dohmer et al., 2014). Furthermore, other key players that are involved in the intracellular life of Brucella include the two-component regulatory system BvrS/BvrR, the cyclic b-glucan, the LuxR-like transcriptional regulator VjbR and the Brucella lipopolysaccharide (LPS) (Sola-Landa et al., 1998; Arellano-Reynoso et al., 2005; Weeks et al., 2010). Recent studies have identified some new players such as the flagellum-like structure, the transporter-like protein BacA and phosphatidylcholine required for intracellular survival within host cells (Roop et al., 2009). In addition to Brucella T4SS, the CD98hc transmembrane protein is recognized as essential for intracellular proliferation and modulates different signaling pathways (Keriel et al., 2015).

Calreticulin is an antigen of endoplasm reticulum that also favors replication in strict rBCVs (replicative Brucella-containing vacuole). Autophagy proteins play an important role in the production of (autophagic Brucella-containing vacuole aBCVs) and pathogen observed in aBCVs contain LAMP1 at the later stage after infection (48-72 h). Finally through the lytic and non-lytic mechanisms, the pathogen is released from the cell (Boschiroli et al., 2002). However, when Brucella reach the ER not only provides a safe niche but it also protects the pathogen from strong bactericidal action of phagocytic cells. New insight in biology of pathogenesis of brucellosis shed lights that Brucella utilizes cell-cycle control system for survival within host intracellular environment similar to Caulobacter crescentus. Brucella is blocked at the G1 stage of growth and resumed replication starts again after reaching within the intracellular compartments (De Bolle et al., 2015). Correspondingly, Brucella is well equipped to tolerate both physiologic and metabolic stresses that essential for its virulence (Kohler et al., 2003). 


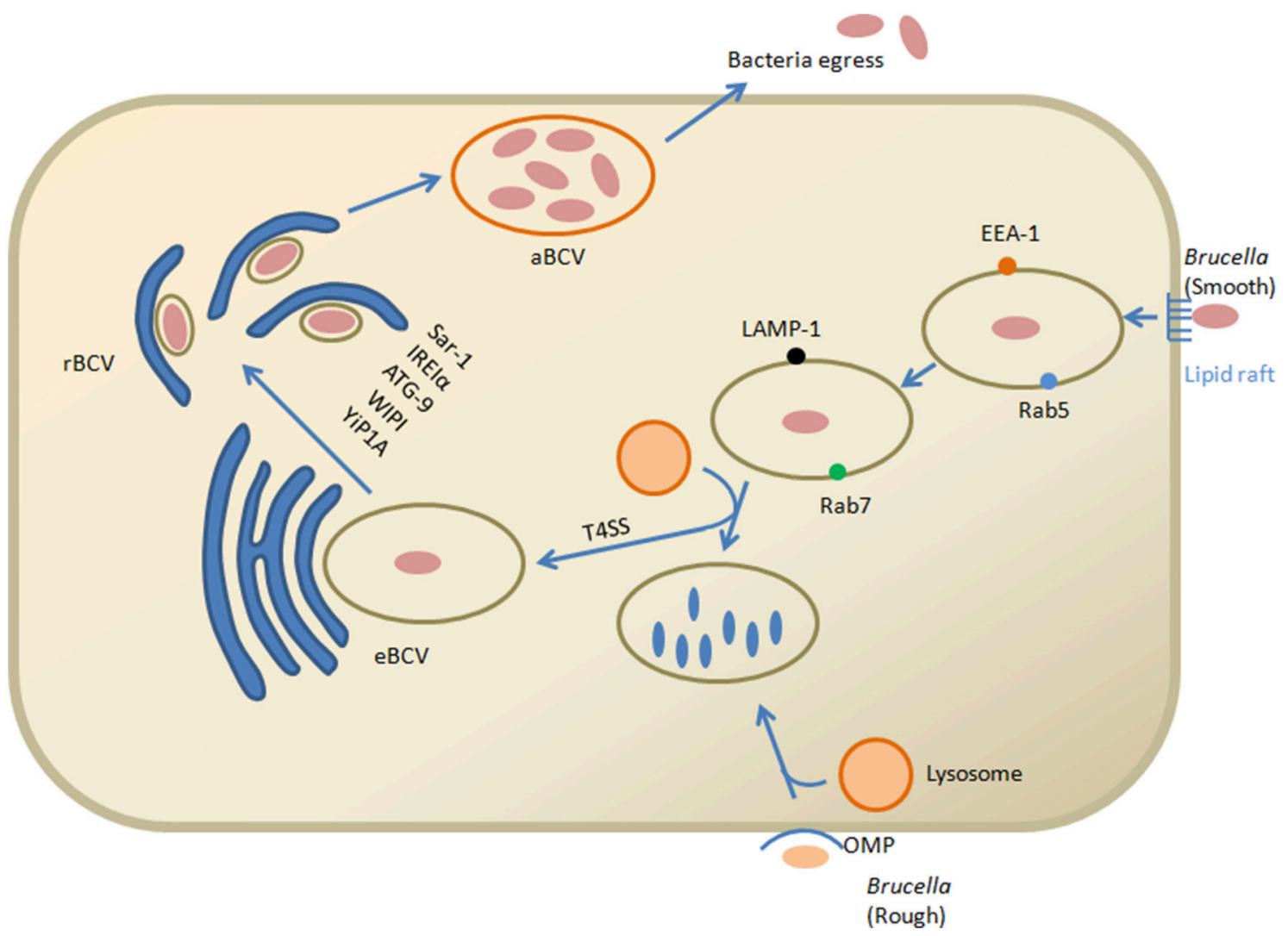

FIGURE 1 | Model of Brucella invasion and intracellular trafficking within macrophage cells. Smooth Brucella and lipid rafts interact on the plasma membrane. Brucella derived $\beta$-1,2-glucans help in the conversion of external vacuole lipid rich domains that leads to fusion with lysosomes for replication of bacteria. This interaction ultimately activates the T4SS proteins. T4SS proteins in the cytosol of host cell facilitate the interaction with the endoplasmic reticulum that converted into the replicative vacuole. Conversion of the eBCV into rBCV is facilitated by Yip1A dependent activation of IRE1 $\alpha$ and results in formation of large vacuoles that depend upon ATG9 and WIPI. The aBCVs formation is dependent on the autophagy initiation proteins, ULK1, ATG14L and BECLIN1, that complete the intracellular cycle and finally through Iytic and non-lytic mechanisms the pathogen is released from the cell. While the role of the rough Brucella outer membrane protein has been verified, their internalization and intracellular trafficking is unclear but involved in lysosomal degradation.

\section{BRUCELLA MODULATION OF INNATE IMMUNE RESPONSE}

As an effective pathogen, Brucella has developed well organized strategies that allow it to evolve and interfere with innate immune recognition which ultimately favor the environment for generating adaptive immune response (Diacovich and Gorvel, 2010). The first line of defense against brucellosis include phagocytosis by cells (neutrophils, macrophages and dendritic cells (DC), and natural killer (NK)-cells), different secretion like cytokines and chemokines, recognition of molecules typical for microbe's pathogen-associated molecular patterns (PAMPs) by pattern-recognition receptors (PRRs), and activation of the complement system (Diacovich and Gorvel, 2010).

Neutrophils are one of the most significant short-lived phagocytic cells in innate immune response against microbial pathogens. However, in brucellosis these cells are not stimulated for effective degranulation. Even though, this pathogen does not replicate within these cells, it can survive at initial stage of infection (Riley and Robertson, 1984) and resists killing (Barquero-Calvo et al., 2007). Brucella have different defensive antimicrobial resistance mechanisms against hypohalide, phospholipase A2, cathelicidin, lysozyme, and defensins like reactive oxygen intermediates (ROI) and reactive nitrogen intermediates (RNI) which ultimately help this pathogen during transportation to lymphoid tissues facilitated by neutrophils (Nathan and Shiloh, 2000).

The host ability to identify Brucella as Gram negative bacteria via TLR2, TLR4, and TLR5 are reduced (Iwasaki and Medzhitov, 2004). Consequently, Brucella avoid the generation of specific host response by displaying wrong "bar code" such as neutrophil infiltration at the infection site. Brucella have the ability to survive in vivo that is not increased by NADPH oxidase and neutrophils (even though it can evade them; Barquero-Calvo et al., 2015).

Other than neutrophils, activated NK cells also kill infected targets and act as first line of defense against Brucella (Fernandes et al., 1995). Brucella activate NK cells by inducing antigen presenting cells to release IL-2 and NK cells are converted into killer cells by IL- 2 activation, secretion of IFN- $\gamma$ and production 
of IFN- $\gamma$ which plays an important role in developing a Th1- or Tc1-like response (Gao et al., 2011).

Macrophages and dendritic cells are considered to be key elements of the innate immune response against the intracellular bacteria like Brucella. Within the first few hours after entry, 80$90 \%$ pathogens are killed by macrophages and DCs, while some of them reach the replicative niche as surviving-pathogens (Watarai et al., 2002). Brucella use lipid rafts to enter within both murine macrophages and human monocytes while it uses PI3-kinase and TLR4 receptors to enter DCs (Pei et al., 2008).

The innate immune system recognizes pathogens in various tissues facilitated by PRRs which includes toll-like receptors (TLRs; Iwasaki and Medzhitov, 2004), Nod-like receptors (NLRs; Franchi et al., 2008), RIG-like receptors (RLRs), and complement (Snyderman et al., 1968). By the detection of these receptors, host cells differentiate bacteria from virus by recognizing PAMPs (Hoebe et al., 2004). There are some distinctive products in bacteria such as lipopolysaccharides, flagellin, lipoteichoic acids, and lipoproteins that are recognized by TLR2, TLR4, TLR6, TLR1, and TLR5 receptors (Iwasaki and Medzhitov, 2004). Interaction with bacterial surface carbohydrates (LPS of Gramnegative bacteria) helps in activation of alternative complement pathway.

Brucella produces lipid A that has significant functions in immune evasion mechanism via TLR4. In comparison with other enterobacterial LPS $\left(\mathrm{C}_{12}-\mathrm{C}_{16}\right)$, the pathogen contains longer fatty acid residue $\left(\mathrm{C}_{28}\right)$ and due to this modification in LPS structure which reduces its endotoxic properties by decreasing TLR4 agonist action (Lapaque et al., 2009). In B. abortus mutants, failure in the addition of lipid A with $\mathrm{C}_{28}$ acyl chain consequently leads to severe inflammatory condition than wild-type parent strain and contribute to decreased infectivity within $\mathrm{BALB} / \mathrm{c}$ mice and in macrophages as well (Parent et al., 2007). In addition to evasion of TLR4, Brucella produce flagellin which plays a role in evasion sensing by TLR5 that has no specific TLR5 agonist domain (Andersen-Nissen et al., 2005).

Brucella use other evasion strategies by suppressing innate immune signaling other than producing PAMPs with decreased TLR agonist activity via TIR domain-containing protein designated as Btp1 in B. abortus and TcpB in B. melitensis. However, the detailed mechanism of this protein is still incompletely understood, but evidence suggests that for binding with TIR domain-containing adaptor protein (TIRAP), it competes with myeloid differentiation response gene 88 (MyD88) that ultimately facilitates ubiquitination and degradation of Mal and inhibits both TLR4 and TLR2 signaling (Figure 2; Snyder et al., 2014). Maturation of the dendritic cells and production of pro-inflammatory cytokines like IL-12 and TNF- $\alpha$ after Brucella invasion and internalization is reduced due to this TLR-inhibition (Salcedo et al., 2008). During the early stage of infection Btp1/TcpB seems to be important in the immune-evasive activity, such that at the inoculation site in immune deficient IRF1 mice, there is no systemic spread by B. melitensis t $t p B$ mutant. The weakened phenotype of $t c p B$ mutants for immune-competent mice suggests that Brucella have ability to evade innate immunity by multiple strategies (Radhakrishnan et al., 2009).
As a stealth invader, Brucella LPS also play a pivotal role in reducing deposition of complement constituent $\mathrm{C} 3$ (Barquero-Calvo et al., 2007). C3 covalently binds with hydroxyl residues present on the surface of bacteria. Many pathogens like Salmonella Typhimurium have free hydroxyl residues in their O-polysaccharide that favors binding with C3 while B. abortus has linear homopolymer of 1,2-linked 4,6-dideoxy-4-formamido-alpha-d-mannopyranosyl residues in its O-polysaccharide (Caroff et al., 1984). Generation of proinflammatory complement products like C3a and C5a is prevented by $\mathrm{C} 3$ binding to Brucella $\mathrm{O}$-antigen. Different studies have shown O-antigen plays an important role in facilitating a non-inflammatory response through lipid raft microdomains and macrophage class A scavenger receptor (SR-A; Kim et al., 2004). These studies suggest that key strategies used by Brucella to modulate innate immune mechanism are inhibition to TLR, complement system and involvement of phagocytic cells. However, further studies on maturation of DCs in vivo and the contribution of newly identified protein in the innate immune response as well as their effect on adaptive immune response will be required to more fully understand the establishment of chronic infection.

\section{BRUCELLA IMPRESSIVE MECHANISMS TO EVADE ADAPTIVE IMMUNE RESPONSE}

Even though innate immunity efficiently controls the replication of Brucella at acute phase of infection, a well-organized adaptive immune response is also essential for the chronic stage (Baldwin and Goenka, 2006). Furthermore, Brucella has developed multiple strategies to defeat host defense mechanisms and consequently confirm the establishment of chronic infection (Monack et al., 2004).

For the initiation and control of adaptive immune responses, some cells such as DCs play a significant role (Kapsenberg, 2003). On the other hand, intracellular pathogens have established multiple mechanisms to challenge the function of DCs that ultimately facilitates the pathogen's entry into the host. Brucella has established several strategies which confirm its shifting from innate immune system to the adaptive immune system for evasion into the host immune machinery. Some recent evidence have confirmed the efficient proliferation of this pathogen within DCs both in vitro (Archambaud et al., 2010) and in vivo (Salcedo et al., 2008). Besides the proliferation, hindrance of maturation of DCs by B. abortus 2308 and B. suis 1330 also reported by in vitro studies (Billard et al., 2007; Salcedo et al., 2008). In addition, prior studies have shown that expression of MHC class II, CD80 and CD86 were decreased in the Brucella infected DCs. Incompetent antigen presentation to naïve $T$ cells and inhibition of maturation result in inhibiting secretion of pro-inflammatory cytokines such as IL-12 band TNF- $\alpha$ (Billard et al., 2007). In long lasting vaccine induced immunity, memory adaptive immune responses are important. For clearance of Brucella, IFN- $\gamma$-mediated type I immune responses are essential (Goenka et al., 2011). Brucella modulates MHC-I and MHC-II expression prompted by IFN$\gamma$, a mechanism that depends on cytokine regulation (Gentilini 
et al., 2015), which results in inhibition of MHC-I and MHC-II molecules (Barrionuevo et al., 2008, 2013).

In brucellosis, adaptive immune response mechanisms are divided in three main steps: in the first step it inhibit the intracellular survival of Brucella, IFN- $\gamma$ produced by CD4+, $\mathrm{CD} 8+$, and $\mathrm{T}$ cells which initiates the bactericidal function in macrophages. Secondly, infected macrophages are killed which lead to cytotoxicity by $\mathrm{CD} 8+$, and $\mathrm{T}$ cells. Thirdly, in the endocytic compartments opsonization of Brucella occur by IgG2a and IgG3 to enhance phagocytosis (Goenka et al., 2011; Martirosyan et al., 2011). Additionally, IL-12, IFN- $\gamma$, and TNF- $\alpha$ are key cytokines in brucellosis, initiating innate and adaptive immune response and giving directions to immuneassociated cells (Martirosyan et al., 2011; Durward et al., 2012). Furthermore, Brucella LPS also successfully enhances Th1-type cytokine response such as IL-10 and IFN- $\gamma$ (Kianmehr et al., 2015) while 5-Lipoxygenase down regulates the manifestation of Th-1 immune response particularly IL-12 in Brucella infection in macrophages (Fahel et al., 2015).

Brucella has a unique property to survive within the host which results in the establishment of chronic infection. Therefore, strong immune regulation events are essentially required in brucellosis. In chronic brucellosis, immunosuppressive state establishes with the concomitant increase of $\mathrm{CD} 4+, \mathrm{CD} 25+\mathrm{T}$ cells in spleen, which ultimately plays a significant role in the regulation of effector $\mathrm{T}$ lymphocytes (Pasquali et al., 2010). These murine CD4+ or CD25+ T cells encourage the elimination of Brucella from infected by antibody depletion (Pasquali et al., 2010). In comparison MHC class II and $\mathrm{CD} 4+\mathrm{Ab}$-deficient mutant mice are more able to eliminate Brucella than in wild type mice. The decrease of Møs and DCs recruitment causes reduced activation of $\mathrm{CD} 8+\mathrm{T}$ lymphocytes that results in immunosuppression (Hort et al., 2003) and deficient clearance of Brucella from spleens, lymph nodes and livers (Rolan and Tsolis, 2007).

In addition to this, Brucella interfere with the establishment of protective Th1 immune response by avoiding secretion of IL12 and preventing the T-cell stimulatory action of infected DCs (Salcedo et al., 2008). As a result, maturation capacity of DCs is reduced and characterized by decreased expression of MHC class II indicating co-stimulatory molecules on the external cell surface are necessary to present exogenous protein antigens to particular T cells (Billard et al., 2007; Salcedo et al., 2008). Mature DCs are capable of having unique tolerogenic properties, and Brucella inhibits complete activation DCs by using this property to subvert immune responses. There is certain evidence that suggests that initiation of tolerance is not limited to undeveloped DCs, however fully mature DCs are able to induce tolerance which ultimately results in the establishment of long-term chronic infection (Lutz and Schuler, 2002). Moreover, contact of immature DCs with CD4+ naïve T cells may induce regulatory T-cell action of Tregs and prevents Th1 response in a TGF$\beta$-dependent manner, this incidence was previously recorded during human chronic brucellosis (Elfaki and Al-Hokail, 2009). Additionally, Brucella infected macrophages activate DCs to present antigen which stimulates immune response of host (Billard et al., 2007). Ineffective contact of CD4+ T cells with immature DCs results in failure in delivery of licensing signals required for $\mathrm{CD} 8+$ cytotoxic $\mathrm{T}$ cell stimulation. Reduction in the level of IL-10 indicates an improvement in host resistance mechanism to brucellosis (Smith et al., 2004). These findings suggest that Brucella hinder antigen presentation, and have significant role in the interplay between innate and adaptive immune mechanisms.

Brucella LPS has noncononical structural differences that play important roles in its stealthy behavior which in turn helps in the initiation of the adaptive immune response and antigen presentation to T cells (Conde-Alvarez et al., 2012). LPS forms macrodomain clusters after recycling from compartments that are specialized sites for antigen loading and processing to macrophage cell surface. These macrodomain clusters are composed of Brucella LPS, MHC class II molecules and lipid rafts. MHC class II molecules form complexes that facilitate the initiation of immune response (Lapaque et al., 2006). Indeed, purified Brucella LPS is capable of inhibiting peritoneal macrophages presentation of ovalbumin and hen egg lysozyme antigenic peptides to specific T-cell hybridomas in the presence of MHC class II (Forestier et al., 2000). At the plasma membrane of peritoneal macrophages, Br-LPS moieties sequester with MHC class II molecules where their biogenesis occurs in lysosomes. Similarly, in B lymphocytes, these Br-LPS moieties also aggregate in the MHC class II compartments (Figure 2; Forestier et al., 1999). B-cell proliferation is initiated by the secretion of Brucella virulence factor prpA that interact with macrophages and release several soluble factors necessary for establishing chronic infection (Spera et al., 2006, 2013). In addition to this, Brucella change the cytokine level of IFN- $\gamma$, TNF- $\alpha$, IL-10 and TGF $\beta 1$ in the early stages of brucellosis in a prpA dependent manner (Spera et al., 2014). Recent studies clarify the roles of Btp1/TcpB, BrLPS and PrpA as being significant immunomodulatory molecules with the ability to interplay with host immune mechanisms. Furthermore, they have capability to inhibit the secretion of IFN$\gamma$ and increase the secretion of IL-10 that affects Th1 immune response (Wang et al., 2012).

Brucella effector molecules are capable of controlling TLR signaling pathway that involved in DC maturation with significant effects on T-lymphocyte activation and antigen presentation. Brucella TIR protein 1 (Btp1) shows sequence resemblances with Toll/IL-1 recptors (TIR) domain family. Different studies investigated the role of Btp1 in DC maturation due to significance of TIR domain in the TLR signaling (Kenny and O'Neill, 2008; Atluri et al., 2011). Btp1 inhibits both the production of proinflammatory cytokines and DC maturation that leads to inhibition of TLR2 and TLR4 signaling (Salcedo et al., 2008; Atluri et al., 2011). Brucella lumazine synthase also induces negative effect by blocking TLR4-MD2 complex (Rossi et al., 2015). Btp1/TcpB bind adapter TIRAP at the cell membrane and block NF- $\kappa$ B activation (Radhakrishnan and Splitter, 2010). Therefore, Brucella inhibits TLR-signaling pathway to reduce the function of infected DCs. Recently, it has been demonstrated that Btp1 associates with host microtubules to protect them from depolymerization an additional function of this protein (Radhakrishnan et al., 2011). Additionally, it has been shown that this protein causes inhibition of CD8+ T-cell killing of Brucella 


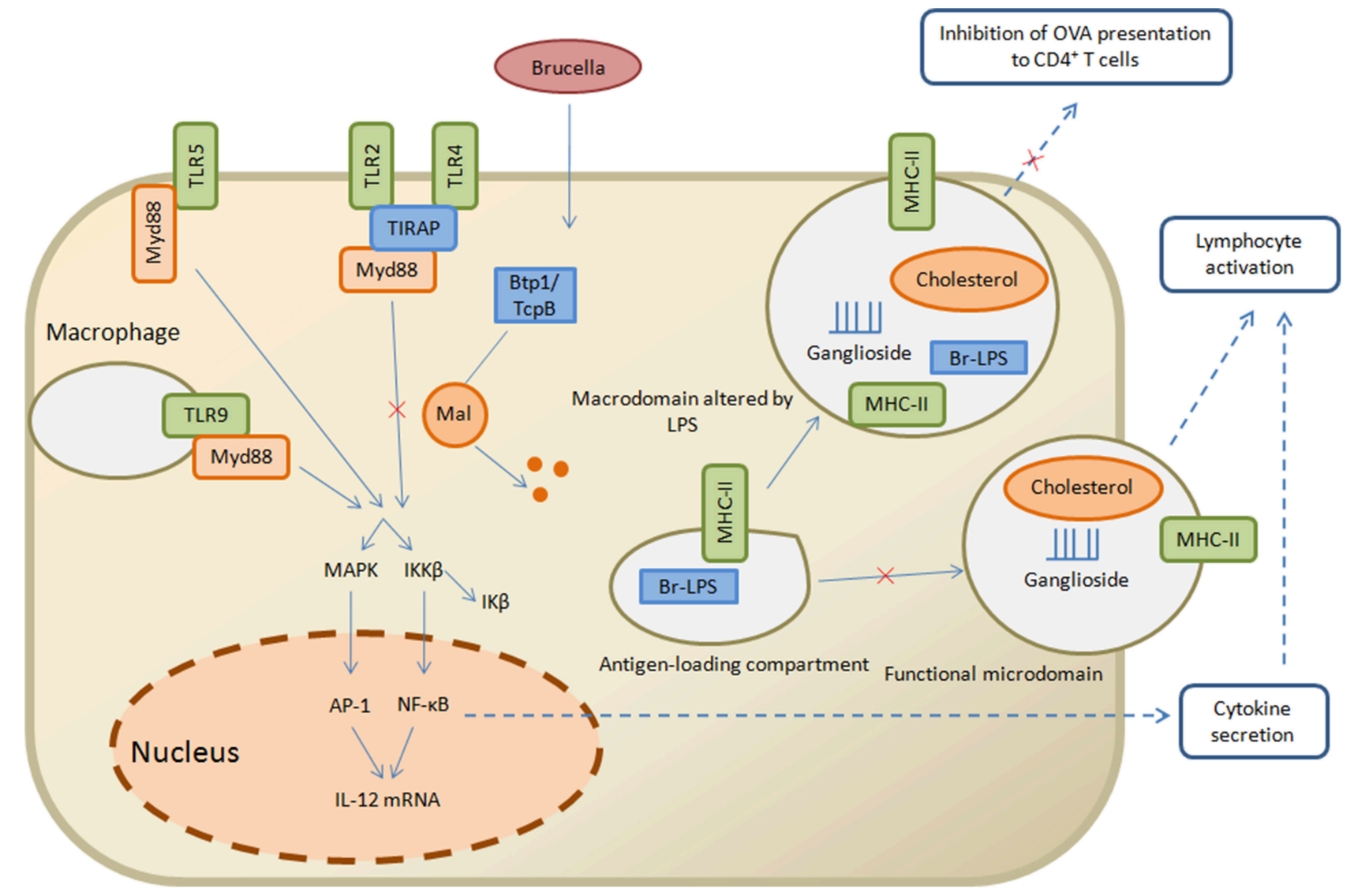

FIGURE 2 | Strategies of Brucella to evade the innate and adaptive immunity. Brucella Btp1/TcpB is proposed to act in host cytosol where it interferes with TLR signaling pathway and facilitates ubiquitination and degradation of Mal which in turn inhibits TLR2 and TLR4 pathway, resulting in inhibition of NF- $\mathrm{B}$ secretion and lymphocyte activation. On the other hand, the antigen loading compartment, comprised of Br-LPS and MHC class II molecules, is capable of interacting with functional microdomain which result in lymphocyte activation and inhibition of OVA presentation to CD4+ T cells. Straight arrows indicate the innate immunity pathways while dashed arrows are related to adaptive immunity pathways.

target cells and represents an adaptive immune evasion strategy (Durward et al., 2012). Thus, these findings of new effector proteins that are capable of interaction with TLR signaling pathway reinforce the notion that Brucella use multiple strategies to evade host adaptive immune system to establish chronic infection (Gorvel, 2008).

\section{SELECTIVE SUBVERSION OF AUTOPHAGY PATHWAY}

Autophagy, "self-eating," contributes to several cellular and organism homeostatic mechanisms by capture of cytosolic components, damaged organelles such as mitochondria, protein aggregates (Kraft and Martens, 2012), and intracellular bacteria (whether cytosolic or vacuolar) into specialized doublemembrane vacuoles called autophagosomes (Yang and Klionsky, 2010). Even though, autophagy is initially found in nutrient reprocessing in response to starvation, some other cellular and oxidative stress functions are well recognized in the induction of autophagy pathway and also contribute to innate immune response (Levine et al., 2011) through antibacterial activities.
Intracellular pathogens adopt different strategies for involvement in the host autophagic pathway that include damage to the membrane, hiding to avoid recognition by the autophagy mechanism and development of replicative niches (Bestebroer et al., 2013).

For the development of Brucella replication ( $\mathrm{rBCV}$ ) fusion of endoplasmic reticulum with endocytic compartment occurs in the Sar1- and Rab2- dependent manner. In macrophages and epithelioid cells during early stages of brucellosis, $\mathrm{rBCV}$ convert into a specialized property compartment known as autophagic BCV (aBCV). Recent evidence supports the theory that autophagy-associated proteins play a key role in the biogenesis of rBCV and contribute to completion of intracellular life cycle, Brucella subverts the host cell membrane trafficking pathways (Starr et al., 2008, 2012).

However, rBCV to aBCV conversion depends upon autophagy initiation proteins for example BECLIN1, PI3K, ULK1, and Atg14L but independently of autophagy elongation proteins such as Atg5, Atg7, LC3B, Atg4B, and Atg16L1 that are necessary for abolishing the autophagosome formation (Starr et al., 2012). The mechanism involved is still not clearly explained, other 
studies suggest that ULK1 and Beclin 1 are required for noncanonical pathways but independent of LC3 and Atg7, as well as Atg5 recruitment (Collins et al., 2009; Nishida et al., 2009). Furthermore, aBCV formation depends upon the small GTPase Rab9 which is not required in HeLa cells (Starr et al., 2012). Autophagosome maturation initiates into endocytic compartment when BECLIN1 and PI3K form a complex, but depletion in ATG14L leads to decreased aBCV formation which starts from the endoplasmic reticulum-localized BECLIN1 complex. Recent studies support the non-canonical autophagy pathway playing a key role in host-pathogen interaction, and have common upstream regulators with canonical autophagy pathway (Starr et al., 2012). The egress mechanism is helpful in pathogen release and cell-to-cell spread in which Atg proteins play a significant role in this process (Duran et al., 2010; Manjithaya and Subramani, 2011).

There are some new insights about the role of unfolded protein response (UPR) and autophagy in Brucella replication and rBCV biogenesis (de Jong et al., 2013; Celli and Tsolis, 2015), such as activation of IRE1 $\alpha$ in macrophages and HeLa cells by B. abortus (Taguchi et al., 2015), while ATF6, PERK and IRE1 $\alpha$ in the instance of B. melitensis infection (Smith et al., 2013). The UPR pathways activation by Brucella also supports the idea that IRE1 $\alpha$ is important in the bacterial replication (Qin et al., 2008). Yip1A is a host protein that leads to phosphorylation of IRE1 $\alpha$ in brucellosis and binding with COPII for localization into Endoplasmic reticulum exist sites. Furthermore, Yip1A and IRE $1 \alpha$ are essential for Brucella replication and $\mathrm{rBCV}$ biogenesis (Taguchi et al., 2015). There is up regulation of Sarl and COPII by Yip1A-dependent activation of IRE1 $\alpha$, results in formation of large vacuoles that depend upon ATG9 and WIPI (Taguchi et al., 2015). These findings clarify the role of IRE1 $\alpha$ in brucellosis and facilitate the formation of autophagic origin vacuoles that convert endosomal brucella-containing vacuole (eBCV) into rBCV (Figure 1; Wang et al., 2014).

It is also observed that UPR activation in the Brucella-infected macrophages via TcpB facilitates protein folding that affects Brucella intracellular growth (Smith et al., 2013). In addition to this some effectors, such as $\mathrm{BspC}, \mathrm{BspK}, \mathrm{BspH}$, and $\mathrm{BspG}$, can also enhance the endoplasm reticulum stress by ecoptic expression in HeLa cells (Myeni et al., 2013). These results show that the initiation of autophagy proteins is important in conversion of $\mathrm{rBCV}$ to $\mathrm{aBCV}$ while Yip1A is also required in Brucella replication and $\mathrm{rBCV}$ biogenesis. Hence, this is an essential strategy used by Brucella to combat with host immune response for which further study is required to investigate the involvement of autophagy in Brucella pathogenesis as well as in innate and adaptive immune mechanisms.

\section{INHIBITION OF APOPTOSIS}

Apoptosis is an extremely well-regulated manner of programmed cell death, which is generally facilitated by the initiation of caspases, and excellent host defense response against intracellular bacteria. However, inhibition of apoptosis is another strategy of Brucella to maintain intracellular niche for its replication.
Brucella inhibits apoptotic mechanism in infected macrophages with the induction of chemical stimuli (Gross et al., 2000). Furthermore, in $B$. melitensis infection there is down regulation of genes involved in apoptotic pathway in mitochondria $(\mathrm{He}$ et al., 2006). There is significant increase in Nedd4 activity during brucellosis in a specific calcium-dependent manner. Brucella-infected macrophages treated with Nedd4 decrease this activity that in turn stops calpain 2 degradation and leads to macrophages apoptosis (Cui et al., 2014). Caspase-2 is involved in the regulation of many genes and pathways which prompts macrophage death that is an important feature of apoptosis and pyroptosis (Bronner et al., 2013). Moreover, upregulation of A20 leads to inhibition of NF- $\kappa$ B that limiting caspase-8-dependent macrophage cell death and favors intracellular growth of bacteria (Wei et al., 2015).

Another important strategy that is employed involves the interaction of Brucella-macrophage to enhance virulence by inhibiting macrophage cell death. After the invasion of smooth Brucella into macrophages for replication, the pathogen automatically converts into rough mutants that can results in macrophage cytotoxicity that favors bacterial egress and dissemination (Pei et al., 2014). B. abortus 2308 rough mutants that lack of surface LPS exhibited failure in the inhibition of apoptosis (Pei et al., 2006), because this depends upon T4SS and is associated with the effect of LPS inhibiting TLR signaling (Pei et al., 2008).

Brucella lipoprotein increases T cells apoptosis which depends upon TNF- $\alpha$ secretion, sheding light on mechanisms that Brucella uses to directly inhibit $\mathrm{T}$ cells responses, involved in adaptive immune evasion (Figure 3; Velasquez et al., 2012). Additionally, Brucella- infected neutrophils and monocytes have obvious upregulation of various adhesion molecules such as CD106 and CD54 that result in inhibition of apoptosis in brucellosis (Scian et al., 2013). Altogether this evidence indicates that apoptosis inhibition is a strategy of Brucella for intracellular replication that in turn facilitates evasion of the immune response.

\section{PUTATIVE ROLE OF SMALL NONCODING RNA AGAINST BRUCELLA STEALTH STRATEGY}

MicroRNAs are part of small noncoding RNA involved in regulation of gene expression and in cellular mechanisms, apoptosis and signal transduction ( $\mathrm{He}$ and Hannon, 2004; Djuranovic et al., 2012; Leung and Sharp, 2013). Even though, we are still at the initial stages of knowing the role of miRNAs and how they develop and regulate the immune mechanisms, recent evidence found that miRNAs play a pivotal role in immunity such as miR-181a and miR-223 in establishing and maintaining immune cells (Chen et al., 2004; Matsushima et al., 2011), miR146 regulate TLR signaling and cytokine response in innate immunity (Tili et al., 2007). Furthermore, they are involved in adaptive immunity associated antigen presentation such as miR-155 (Schulte et al., 2013), and miR-181a in T cell receptor signaling (Iliopoulos et al., 2010). 


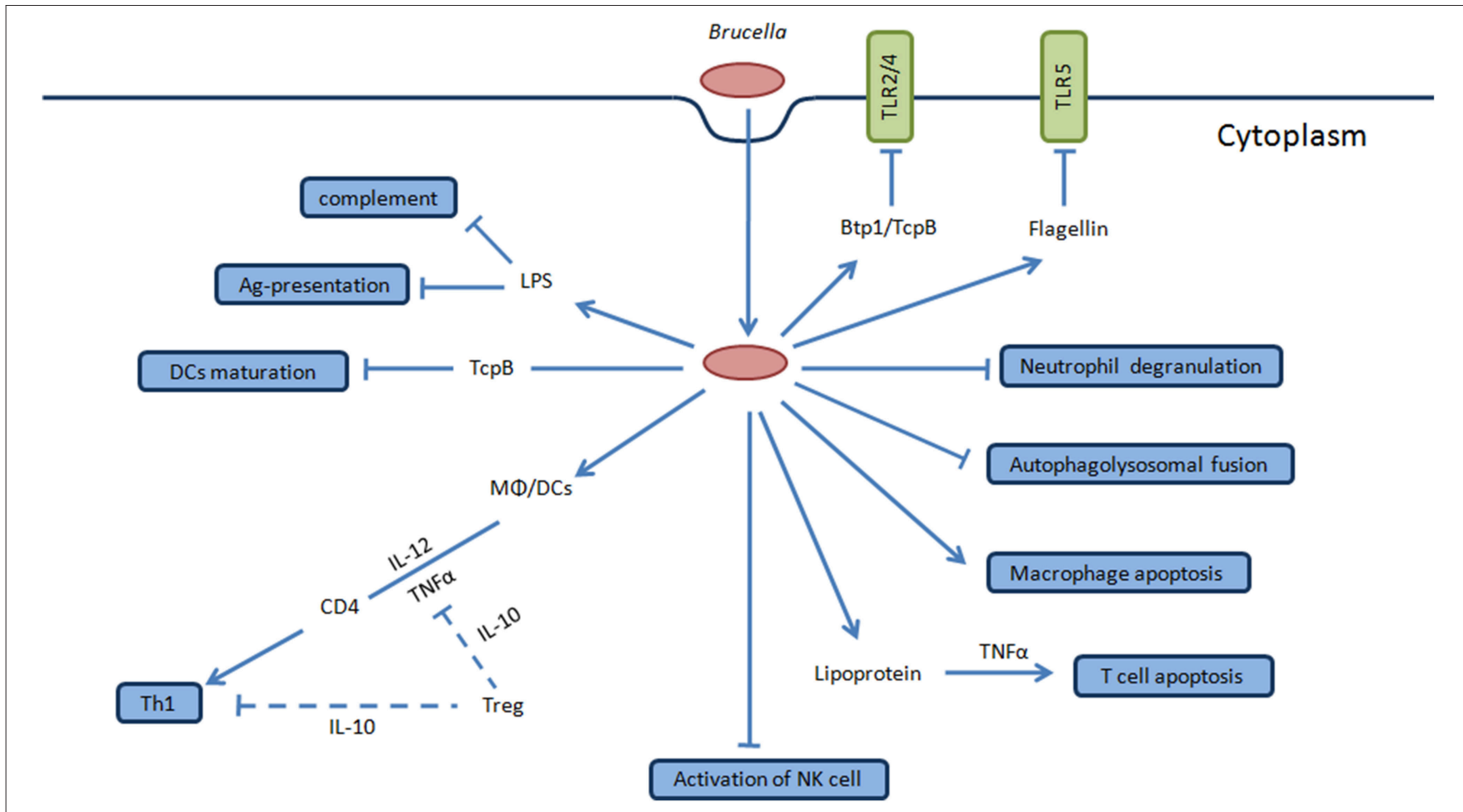

FIGURE 3 | Overview of stealth strategies of Brucella. TLR signaling pathway is involved in the recognition of Brucella which mediates the secretion of TNF- $\alpha$ and IL-12 by DCs and Møs during the initial stages of infection that favor intracellular survival and replication. Brucella produces Btp1/TcpB protein that inhibits TLR2/4 signaling pathway while flagellin inhibits TLR5. Brucella LPS O-antigen binds with C3 preventing activation of complement cascade. Brucella inhibits activation of NK cells and neutrophil degranulation to interfere with innate immune response of host. Btp1/TcpB produced by this bacteria inhibit dendritic cells maturation, and Brucella LPS inhibits of antigen presentation, coupled together ultimately interfere with innate and adaptive immunity of host facilitating chronic infection. Brucella lipoprotein increases apoptosis of T cells which is dependent upon TNF- $\alpha$ secretion that directly inhibits the T cell response. Furthermore, Brucella inhibits macrophage apoptosis and autophagolysosomal fusion which are among the key stealth strategies of this pathogen. The final consequence of interfering with these mechanism results in the clinical manifestations of human brucellosis and in the natural hosts.

Brucella adapt diverse environmental conditions and use multiple strategies to evade host cell defense. It would seem that Brucella sRNA may play a significant role in bacterial responses to stress. Hfq protein mediates most of the sRNAmRNA interactions which is required for virulence and to control bacterial stress response in pathogen-host interactions (Papenfort and Vogel, 2010; Hanna et al., 2013) as well in Brucella stress response (Robertson and Roop, 1999). A recent finding also supports the involvement of hfq in pathogenicity associated invasion and proliferation within host cell as illustrated by a B.melitensis hfq mutant (Cui et al., 2013).

Casewell et al. reported that $B$. abortus sRNAs, abcR1 and abcR2 play essential roles in pathogenicity and in chronic infection, resulting in a significant decrease in intracellular survival in a mouse model and in macrophages as well (Caswell et al., 2012). Transcriptional regulators like gntR code for miRNAs required for Brucella virulence. However, their inhibited expression within macrophages led to decreased Brucella intracellular survival indicating that miRNAs are essential for the adaptation to stress conditions and ultimately cause modulation of Brucella intracellular survival (Wang et al., 2015).

Inhibited expression of syntaxin mRNA with small interfering RNAs modulated initial phagocytosis and intracellular survival of Brucella (Castaneda-Ramirez et al., 2015). We studied the expression of miRNAs in B. melitensis-infected cells and found several miRNAs such as miR-92a, miR-93, let-7b, miR-1981, and miR-181b differentially expressed compared to mock-infected cells, and purposed that these miRNAs might be involved in immune response mechanisms, autophagy and apoptosis (Zheng et al., 2012). These reports shed light on the importance of small noncoding RNA in immunity, but further studies will be required to more fully understand the involvement and mechanism of miRNAs in modulating the host immune response as well as miRNA-based strategies used by Brucella for immune evasion.

\section{SUMMARY AND PERSPECTIVES}

Although in brucellosis humans are infected as incidental host, approximately 500,000 new cases reported annually, yet no patient-friendly treatment or effective vaccines available for humans. Additionally, Brucella spp. shows deliberate release through direct discharge to poses risk to public health. Brucella has remarkable strategies enabling avoidance of the host immune response and facilitating the establishment of chronic infections. However, for survival the host cells have developed complex immune mechanisms to defeat and battle against pathogens 
and maintain a balance between host resistance and Brucella virulence. During the intracellular replication Brucella shows typical tissue tropism for lymphoreticular and reproductive systems that helps in evasion of innate and adaptive immune mechanism of host to establish clinical disease manifestations and pathogenesis. At the early stage of infection symptoms observed in humans includes, fatigue, pyrexia, anorexia, myalgia and diaphoresis. However, during chronic stage of brucellosis, persistence occurs in the tissues of mononuclear phagocyte system including bone marrow, lymph nodes, liver and spleen. Likewise it also persists in male reproductive organs, placenta and fetus. At early process of infectious pathogenesis, Brucella modulate the immune response mechanism of host to quickly translocate through mucosal immune barrier and is endocytosed by mucosal macrophages and DCs. Stealthy brucellae use different type of strategies to establish and maintain chronic infection by fusion of type IV secretary system dependent BCVs with lysosome to evade intracellular destruction. Brucella infects the host cell and protects itself by limiting PRRs including complement system and TLR signaling pathways. Brucella LPS shows non-cononical structural differences that inhibit antigen presentation to T cells and dampens innate and adaptive immune mechanisms. Moreover, Brucella LPS inhibits activation of DCs to subvert the immune response and establish protective Th1 immune response by secreting IL-12 and preventing T-cell stimulatory action. Brucella modulates MHC-I and MHC-II expression prompted by IFN- $\gamma$ which depend upon cytokine regulation. In addition, Brucella uses multiple strategies such as cloaking to avoid recognition by the autophagy mechanism and development of replicative niches. Furthermore, inhibition of apoptosis is another strategy of Brucella to evade the immune response to establish chronic infection.

Once Brucella adapted to the intra-macrophage environment it extends intracellular replication to reach other systems preferably to target cells and tissues such as skeletal tissues, male

\section{REFERENCES}

Andersen-Nissen, E., Smith, K. D., Strobe, K. L., Barrett, S. L. R., Cookson, B. T., Logan, S. M., et al. (2005). Evasion of Toll-like receptor 5 by flagellated bacteria. Proc. Natl. Acad. Sci. U.S.A. 102, 9247-9252. doi: 10.1073/pnas.05020 40102

Archambaud, C., Salcedo, S. P., Lelouard, H., Devilard, E., de Bovis, B., Van Rooijen, N., et al. (2010). Contrasting roles of macrophages and dendritic cells in controlling initial pulmonary Brucella infection. Eur. J. Immun. 40, 3458-3471. doi: 10.1002/eji.201040497

Arellano-Reynoso, B., Lapaque, N., Salcedo, S., Briones, G., Ciocchini, A. E., Ugalde, R., et al. (2005). Cyclic beta-1,2-glucan is a Brucella virulence factor required for intracellular survival. Nat. Immunol. 6, 618-625. doi: $10.1038 /$ ni1202

Atluri, V. L., Xavier, M. N., de Jong, M. F., den Hartigh, A. B., and Tsolis, R. M. (2011). Interactions of the human pathogenic Brucella species with their hosts. Annu. Rev. Microbiol. 65, 523-541. doi: 10.1146/annurev-micro-090110102905

Baldwin, C. L., and Goenka, R. (2006). Host immune responses to the intracellular bacteria Brucella: does the bacteria instruct the host to facilitate chronic infection? Crit. Rev. Immunol. 26, 407-442. doi: 10.1615/CritRevImmunol.v26.i5.30 genitalia, placental trophoblasts, reticuloendothelial system and endothelium. Newly identified protein UPR and Btp1/TcpB are also important in innate immune evasion during early stages of infection. Recent evidence suggests that Yip1A and IRE1 $\alpha$ are essential for Brucella replication and $\mathrm{rBCV}$ biogenesis that ultimately supports nutrient acquisition and pathogen cell-tocell spread. Even though numerous strategies employed by Brucella to evade the immune response have been identified, there are many questions that need to be answered in respect to other "stealth" mechanisms. What mechanism is involved in apoptosis inhibition by Brucella in infected host cells remains to be clarified? How do miRNAs interfere with innate and adaptive immune response mechanisms? How miRNAs cause modulation in Brucella intracellular survival? What is the role of miRNAs in autophagy and apoptosis mechanism will be an open question for the next few years. In depth understanding of the "stealth" strategies used by this pathogen will facilitate focus on the pathogenicity of bacterium and development of novel effective therapeutic approaches to treat brucellosis in the future.

\section{AUTHOR CONTRIBUTIONS}

WA and ZL designed the research and wrote the manuscript. $\mathrm{KZ}$ helped to prepared the figures. ZL revised the manuscript critically for relevant intellectual content. All authors have read and approved the manuscript.

\section{ACKNOWLEDGMENTS}

This work was supported by National Basic Research Program of China (973 Program) (2010CB530200) and Special Fund for Agro-scientific Research in the Public Interest (201303042) to ZL. We thank Dr. Leslie Garry Adams, Texas A\&M University, United States of America, for discussion and suggestions.

Barquero-Calvo, E., Chaves-Olarte, E., Weiss, D. S., Guzman-Verri, C., ChaconDiaz, C., Rucavado, A., et al. (2007). Brucella abortus uses a stealthy strategy to avoid activation of the innate immune system during the onset of infection. PLoS ONE 2:631. doi: 10.1371/journal.pone.0000631

Barquero-Calvo, E., Mora-Cartin, R., Arce-Gorvel, V., de Diego, J. L., ChaconDiaz, C., Chaves-Olarte, E., et al. (2015). Brucella abortus induces the premature death of human neutrophils through the action of its lipopolysaccharide. PLoS Pathog. 11:e1004853. doi: 10.1371/journal.ppat.1004853

Barrionuevo, P., Cassataro, J., Delpino, M. V., Zwerdling, A., Pasquevich, K. A., Samartino, C. G., et al. (2008). Brucella abortus inhibits major histocompatibility complex class II expression and antigen processing through interleukin-6 secretion via toll-like receptor 2. Infect. Immun. 76, 250-262. doi: 10.1128/IAI.00949-07

Barrionuevo, P., Delpino, M. V., Pozner, R. G., Velasquez, L. N., Cassataro, J., and Giambartolomei, G. H. (2013). Brucella abortus induces intracellular retention of MHC-I molecules in human macrophages down-modulating cytotoxic CD8(+) T cell responses. Cell. Microbiol. 15, 487-502. doi: 10.1111/cmi.12058

Bestebroer, J., V'kovski, P., Mauthe, M., and Reggiori, F. (2013). Hidden behind autophagy: the unconventional roles of ATG proteins. Traffic 14, 1029-1041. doi: $10.1111 /$ tra.12091

Billard, E., Dornand, J., and Gross, A. (2007). Brucella suis prevents human dendritic cell maturation and antigen presentation through regulation of 
tumor necrosis factor alpha secretion. Infect. Immun. 75, 4980-4989. doi: 10.1128/IAI.00637-07

Boschiroli, M. L., Ouahrani-Bettache, S., Foulongne, V., Michaux-Charachon, S., Bourg, G., Allardet-Servent, A., et al. (2002). The Brucella suis virB operon is induced intracellularly in macrophages. Proc. Natl. Acad. Sci. U.S.A. 99, 1544-1549. doi: 10.1073/pnas.032514299

Bronner, D. N., O’Riordan, M. X., and He, Y. (2013). Caspase-2 mediates a Brucella abortus RB51-induced hybrid cell death having features of apoptosis and pyroptosis. Front. Cell. Infect. Microbiol. 3:83. doi: 10.3389/fcimb.2013.00083

Caroff, M., Bundle, D. R., Perry, M. B., Cherwonogrodzky, J. W., and Duncan, J. R. (1984). Antigenic S-type lipopolysaccharide of Brucella abortus 1119-3. Infect. Immun. 46, 384-388.

Castaneda-Ramirez, A., Gonzalez-Rodriguez, D., Hernandez-Pineda, J. A., and Verdugo-Rodriguez, A. (2015). Blocking the expression of syntaxin 4 interferes with initial phagocytosis of Brucella melitensis in macrophages. Can. J. Vet. Res. $79,39-45$.

Caswell, C. C., Gaines, J. M., Ciborowski, P., Smith, D., Borchers, C. H., Roux, C. M., et al. (2012). Identification of two small regulatory RNAs linked to virulence in Brucella abortus 2308. Mol. Microbiol. 85, 345-360. doi: 10.1111/j.13652958.2012.08117.x

Celli, J., de Chastellier, C., Franchini, D. M., Pizarro-Cerda, J., Moreno, E., and Gorvel, J. P. (2003). Brucella evades macrophage killing via VirB-dependent sustained interactions with the endoplasmic reticulum. J. Exp. Med. 198, 545-556. doi: 10.1084/jem.20030088

Celli, J., and Tsolis, R. M. (2015). Bacteria, the endoplasmic reticulum and the unfolded protein response: friends or foes? Nat. Rev. Microbiol. 13, 71-82. doi: 10.1038/nrmicro3393

Chen, C. Z., Li, L., Lodish, H. F., and Bartel, D. P. (2004). MicroRNAs modulate hematopoietic lineage differentiation. Science 303, 83-86. doi: 10.1126/science. 1091903

Collins, C. A., De Maziere, A., van Dijk, S., Carlsson, F., Klumperman, J., and Brown, E. J. (2009). Atg5-independent sequestration of ubiquitinated mycobacteria. PLoS Pathog. 5:e1000430. doi: 10.1371/journal.ppat.10 00430

Conde-Alvarez, R., Arce-Gorvel, V., Iriarte, M., Mancek-Keber, M., BarqueroCalvo, E., Palacios-Chaves, L., et al. (2012). The lipopolysaccharide core of Brucella abortus acts as a shield against innate immunity recognition. PLoS Pathog. 8:e1002675. doi: 10.1371/journal.ppat.1002675

Copin, R., Vitry, M. A., Mambres, D. H., Machelart, A., De Trez, C., Vanderwinden, J. M., et al. (2012). In situ microscopy analysis reveals local innate immune response developed around brucella infected cells in resistant and susceptible mice. PLoS Pathog. 8:e1002575. doi: 10.1371/journal.ppat.1002575

Cui, G. M., Wei, P., Zhao, Y. X., Guan, Z. H., Yang, L., Sun, W. C., et al. (2014). Brucella infection inhibits macrophages apoptosis via Nedd4-dependent degradation of calpain2. Vet. Microb. 174, 195-205. doi: 10.1016/j.vetmic.2014.08.033

Cui, M., Wang, T., Xu, J., Ke, Y., Du, X., Yuan, X., et al. (2013). Impact of Hfq on global gene expression and intracellular survival in Brucella melitensis. PLoS ONE 8:e71933. doi: 10.1371/journal.pone.0071933

D’Anastasio, R., Staniscia, T., Milia, M. L., Manzoli, L., and Capasso, L. (2011). Origin, evolution and paleoepidemiology of brucellosis. Epidemiol. Infect. 139, 149-156. doi: 10.1017/S095026881000097X

De Bolle, X., Crosson, S., Matroule, J. Y., and Letesson, J. J. (2015). Brucella abortus cell cycle and infection are coordinated. Trends Microbiol. 23, 812-821. doi: 10.1016/j.tim.2015.09.007

de Figueiredo, P., Ficht, T. A., Rice-Ficht, A., Rossetti, C. A., and Adams, L. G. (2015). Pathogenesis and immunobiology of brucellosis review of Brucellahost interactions. Am. J. Path. 185, 1505-1517. doi: 10.1016/j.ajpath.2015.0 3.003

de Jong, M. F., Starr, T., Winter, M. G., den Hartigh, A. B., Child, R., Knodler, L. A., et al. (2013). Sensing of bacterial type IV secretion via the unfolded protein response. MBio 4, e00418-e00412. doi: 10.1128/mbio.00418-12

Diacovich, L., and Gorvel, J. P. (2010). Bacterial manipulation of innate immunity to promote infection. Nat. Rev. Microbiol. 8, 117-128. doi: 10.1038/nrmicro2295

Djuranovic, S., Nahvi, A., and Green, R. (2012). miRNA-mediated gene silencing by translational repression followed by mRNA deadenylation and decay. Science 336, 237-240. doi: 10.1126/science.1215691
Dohmer, P. H., Valguarnera, E., Czibener, C., and Ugalde, J. E. (2014). Identification of a type IV secretion substrate of Brucella abortus that participates in the early stages of intracellular survival. Cell. Microbiol. 16, 396-410. doi: 10.1111/cmi.12224

Duran, J. M., Anjard, C., Stefan, C., Loomis, W. F., and Malhotra, V. (2010). Unconventional secretion of Acb1 is mediated by autophagosomes. J. Cell Biol. 188, 527-536. doi: 10.1083/jcb.200911154

Durward, M., Radhakrishnan, G., Harms, J., Bareiss, C., Magnani, D., and Splitter, G. A. (2012). Active evasion of CTL mediated killing and low quality responding CD8+ T cells contribute to persistence of brucellosis. PLoS ONE 7:e34925. doi: 10.1371/journal.pone.0034925

Elfaki, M. G., and Al-Hokail, A. A. (2009). Transforming growth factor beta production correlates with depressed lymphocytes function in humans with chronic brucellosis. Microbes Infect. 11, 1089-1096. doi: 10.1016/j.micinf.2009.08.001

Fahel, J. S., de Souza, M. B., Gomes, M. T., Corsetti, P. P., Carvalho, N. B., Marinho, F. A., et al. (2015). 5-Lipoxygenase negatively regulates Th1 response during Brucella abortus infection in mice. Infect. Immun. 83, 1210-1216. doi: 10.1128/IAI.02592-14

Fernandes, D. M., Benson, R., and Baldwin, C. L. (1995). Lack of a role for natural killer cells in early control of Brucella abortus 2308 infections in mice. Infect. Immun. 63, 4029-4033.

Forestier, C., Deleuil, F., Lapaque, N., Moreno, E., and Gorvel, J. P. (2000). Brucella abortus lipopolysaccharide in murine peritoneal macrophages acts as a down-regulator of $\mathrm{T}$ cell activation. J. Immunol. 165, 5202-5210. doi: 10.4049/jimmunol.165.9.5202

Forestier, C., Moreno, E., Pizarro-Cerda, J., and Gorvel, J. P. (1999). Lysosomal accumulation and recycling of lipopolysaccharide to the cell surface of murine macrophages, an in vitro and in vivo study. J. Immunol. 162, 6784-6791.

Franchi, L., Park, J. H., Shaw, M. H., Marina-Garcia, N., Chen, G., Kim, Y. G., et al. (2008). Intracellular NOD-like receptors in innate immunity, infection and disease. Cell. Microbiol. 10, 1-8. doi: 10.1111/j.1462-5822.2007.01059.x

Gao, N., Jennings, P., Guo, Y., and Yuan, D. (2011). Regulatory role of natural killer (NK) cells on antibody responses to Brucella abortus. Innate Immun. 17, 152-163. doi: 10.1177/1753425910367526

Gentilini, M. V., Velasquez, L. N., Barrionuevo, P., Arriola Benitez, P. C., Giambartolomei, G. H., and Delpino, M. V. (2015). Adrenal steroids modulate the immune response during Brucella abortus infection by a mechanism that depends on the regulation of cytokine production. Infect. Immun. 83, 1973-1982. doi: 10.1128/IAI.03090-14

Godfroid, J., Scholz, H. C., Barbier, T., Nicolas, C., Wattiau, P., Fretin, D., et al. (2011). Brucellosis at the animal/ecosystem/human interface at the beginning of the 21st century. Prev. Vet. Med. 102, 118-131. doi: 10.1016/j.prevetmed.2011.04.007

Goenka, R., Parent, M. A., Elzer, P. H., and Baldwin, C. L. (2011). B cell-deficient mice display markedly enhanced resistance to the intracellular bacterium Brucella abortus. J. Infect. Dis. 203, 1136-1146. doi: 10.1093/infdis/jiq171

Gorvel, J. P. (2008). Brucella: a Mr "Hide" converted into Dr Jekyll. Microbes Infect. 10, 1010-1013. doi: 10.1016/j.micinf.2008.07.007

Grillo, M. J., Blasco, J. M., Gorvel, J. P., Moriyon, I., and Moreno, E. (2012). What have we learned from brucellosis in the mouse model? Vet. Res. 43, 1244-1250. doi: 10.1186/1297-9716-43-29

Gross, A., Terraza, A., Ouahrani-Bettache, S., Liautard, J. P., and Dornand, J. (2000). In vitro Brucella suis infection prevents the programmed cell death of human monocytic cells. Infect. Immun. 68, 342-351. doi: 10.1128/IAI.68.1.342351.2000

Hanna, N., Ouahrani-Bettache, S., Drake, K. L., Adams, L. G., Kohler, S., and Occhialini, A. (2013). Global Rsh-dependent transcription profile of Brucella suis during stringent response unravels adaptation to nutrient starvation and cross-talk with other stress responses. BMC Genomics 14:459. doi: 10.1186/1471-2164-14-459

He, L., and Hannon, G. J. (2004). MicroRNAs: small RNAs with a big role in gene regulation. Nat. Rev. Genet. 5:522. doi: 10.1038/nrg1379

He, Y. Q., Reichow, S., Ramamoorthy, S., Ding, X. C., Lathigra, R., Craig, J. C., et al. (2006). Brucella melitensis triggers time-dependent modulation of a apoptosis and down-regulation of mitochondrion-associated gene expression in mouse macrophages. Infect. Immun. 74, 5035-5046. doi: 10.1128/IAI.01 998-05 
Hoebe, K., Janssen, E., and Beutler, B. (2004). The interface between innate and adaptive immunity. Nat. Immunol. 5, 971-974. doi: 10.1038/ni1004-971

Hort, G. M., Weisenburger, J., Borsdorf, B., Peters, C., Banai, M., Hahn, H., et al. (2003). Delayed type hypersensitivity-associated disruption of splenic periarteriolar lymphatic sheaths coincides with temporary loss of IFN-gamma production and impaired eradication of bacteria in Brucella abortus-infected mice. Microbes Infect. 5, 95-106. doi: 10.1016/S1286-4579(02) 00076-X

Iliopoulos, D., Jaeger, S. A., Hirsch, H. A., Bulyk, M. L., and Struhl, K. (2010). STAT3 activation of miR-21 and miR-181b-1 via PTEN and CYLD are part of the epigenetic switch linking inflammation to cancer. Mol. Cell 39, 493-506. doi: 10.1016/j.molcel.2010.07.023

Iwasaki, A., and Medzhitov, R. (2004). Toll-like receptor control of the adaptive immune responses. Nat. Immunol. 5, 987-995. doi: 10.1038/ni1112

Kapsenberg, M. L. (2003). Dendritic-cell control of pathogen-driven T-cell polarization. Nat. Rev. Immunol. 3, 984-993. doi: 10.1038/nri1246

Kenny, E. F., and O'Neill, L. A. J. (2008). Signalling adaptors used by Toll-like receptors: an update. Cytokine 43, 342-349. doi: 10.1016/j.cyto.2008.07.010

Keriel, A., Botella, E., Estrach, S., Bragagnolo, G., Vergunst, A. C., Feral, C. C., et al. (2015). Brucella Intracellular Life Relies on the Transmembrane Protein CD98 Heavy Chain. J. Infect. Dis. 211, 1769-1778. doi: 10.1093/infdis/jiu673

Kianmehr, Z., Soleimanjahi, H., Ardestani, S. K., Fotouhi, F., and Abdoli, A. (2015). Influence of Brucella abortus lipopolysaccharide as an adjuvant on the immunogenicity of HPV-16 L1VLP vaccine in mice. Med. Microbiol. Immunol. 204, 205-213. doi: 10.1007/s00430-014-0356-z

Kim, S., Watarai, M., Suzuki, H., Makino, S., Kodama, T., and Shirahata, T. (2004). Lipid raft microdomains mediate class A scavenger receptordependent infection of Brucella abortus. Microb. Pathog. 37, 11-19. doi: 10.1016/j.micpath.2004.04.002

Kohler, S., Michaux-Charachon, S., Porte, F., Ramuz, M., and Liautard, J. P. (2003). What is the nature of the replicative niche of a stealthy bug named Brucella? Trend Microbiol. 11, 215-219. doi: 10.1016/S0966-842X(03)00078-7

Kraft, C., and Martens, S. (2012). Mechanisms and regulation of autophagosome formation. Curr. Opin. Cell Biol. 24, 496-501. doi: 10.1016/j.ceb.2012.05.001

Lapaque, N., Muller, A., Alexopoulou, L., Howard, J. C., and Gorvel, J. P. (2009). Brucella abortus induces Irgm3 and Irga6 expression via typeI IFN by a MyD88-dependent pathway, without the requirement of TLR2, TLR4, TLR5 and TLR9. Microb. Pathogenesis 47, 299-304. doi: 10.1016/j.micpath.2009.09.005

Lapaque, N., Takeuchi, O., Corrales, F., Akira, S., Moriyon, I., Howard, J. C., et al. (2006). Differential inductions of TNF-alpha and IGTP, IIGP by structurally diverse classic and non-classic lipopolysaccharides. Cell. Microbiol. 8, 401-413. doi: $10.1111 / j .1462-5822.2005 .00629 . x$

Leung, A. K., and Sharp, P. A. (2013). Quantifying Argonaute proteins in and out of GW/P-bodies: implications in microRNA activities. Adv. Exp. Med. Biol. 768, 165-182. doi: 10.1007/978-1-4614-5107-5_10

Levine, B., Mizushima, N., and Virgin, H. W. (2011). Autophagy in immunity and inflammation. Nature 469, 323-335. doi: 10.1038/nature09782

Lutz, M. B., and Schuler, G. (2002). Immature, semi-mature and fully mature dendritic cells: which signals induce tolerance or immunity? Trends Immunol. 23, 445-449. doi: 10.1016/S1471-4906(02)02281-0

Manjithaya, R., and Subramani, S. (2011). Autophagy: a broad role in unconventional protein secretion? Trend Cell Biol 21, 67-73. doi: 10.1016/j.tcb.2010.09.009

Martirosyan, A., and Gorvel, J. P. (2013). Brucella evasion of adaptive immunity. Future Microbiol. 8, 147-154. doi: 10.2217/fmb.12.140

Martirosyan, A., Moreno, E., and Gorvel, J. P. (2011). An evolutionary strategy for a stealthy intracellular Brucella pathogen. Immunol. Rev. 240, 211-234. doi: 10.1111/j.1600-065X.2010.00982.x

Matsushima, K., Isomoto, H., Inoue, N., Nakayama, T., Hayashi, T., Nakayama, M., et al. (2011). MicroRNA signatures in Helicobacter pylori-infected gastric mucosa. Int. J. Cancer 128, 361-370. doi: 10.1002/ijc.25348

Monack, D. M., Mueller, A., and Falkow, S. (2004). Persistent bacterial infections: the interface of the pathogen and the host immune system. Nat. Rev. Microbiol. 2, 747-765. doi: $10.1038 /$ nrmicro955

Myeni, S., Child, R., Ng, T. W., Kupko, J. J. III, Wehrly, T. D., Porcella, S. F., et al. (2013). Brucella modulates secretory trafficking via multiple type IV secretion effector proteins. PLoS Pathog. 9:e1003556. doi: 10.1371/journal.ppat.1003556
Nathan, C., and Shiloh, M. U. (2000). Reactive oxygen and nitrogen intermediates in the relationship between mammalian hosts and microbial pathogens. Proc. Natl. Acad. Sci. U.S.A. 97, 8841-8848. doi: 10.1073/pnas.97.16.8841

Nishida, Y., Arakawa, S., Fujitani, K., Yamaguchi, H., Mizuta, T., Kanaseki, T., et al. (2009). Discovery of Atg5/Atg7-independent alternative macroautophagy. Nature 461, 654-U699. doi: 10.1038/nature08455

Papenfort, K., and Vogel, J. (2010). Regulatory RNA in bacterial pathogens. Cell Host Microbe 8, 116-127. doi: 10.1016/j.chom.2010.06.008

Pappas, G., Papadimitriou, P., Akritidis, N., Christou, L., and Tsianos, E. V. (2006). The new global map of human brucellosis. Lancet Infect. Dis. 6, 91-99. doi: 10.1016/S1473-3099(06)70382-6

Parent, M. A., Goenka, R., Murphy, E., LeVier, K., Carreiro, N., Golding, B., et al. (2007). Brucella abortus bacA mutant induces greater pro-inflammatory cytokines than the wild-type parent strain. Microbes Infect. 9, 55-62. doi: 10.1016/j.micinf.2006.10.008

Pasquali, P., Thornton, A. M., Vendetti, S., Pistoia, C., Petrucci, P., Tarantino, M., et al. (2010). CD4+CD25+ T regulatory cells limit effector T cells and favor the progression of brucellosis in BALB/c mice. Microbes Infect. 12, 3-10. doi: 10.1016/j.micinf.2009.09.005

Pei, J., Kahl-McDonagh, M., and Ficht, T. A. (2014). Brucella dissociation is essential for macrophage egress and bacterial dissemination. Front. Cell Infect Microbiol. 4:23. doi: 10.3389/fcimb.2014.00023

Pei, J., Turse, J. E., and Ficht, T. A. (2008). Evidence of Brucella abortus OPS dictating uptake and restricting NF-kappaB activation in murine macrophages. Microbes Infect. 10, 582-590. doi: 10.1016/j.micinf.2008.01.005

Pei, J., Turse, J. E., Wu, Q., and Ficht, T. A. (2006). Brucella abortus rough mutants induce macrophage oncosis that requires bacterial protein synthesis and direct interaction with the macrophage. Infect. Immun. 74, 2667-2675. doi: 10.1128/IAI.74.5.2667-2675.2006

Qin, Q. M., Pei, J., Ancona, V., Shaw, B. D., Ficht, T. A., and de Figueiredo, P. (2008). RNAi screen of endoplasmic reticulum-associated host factors reveals a role for IRE1 alpha in supporting Brucella replication. PLoS Pathog 4:e1000110. doi: 10.1371/journal.ppat.1000110

Radhakrishnan, G. K., Harms, J. S., and Splitter, G. A. (2011). Modulation of microtubule dynamics by a TIR domain protein from the intracellular pathogen Brucella melitensis. Biochem. J. 439, 79-83. doi: 10.1042/BJ20110577

Radhakrishnan, G. K., and Splitter, G. A. (2010). Biochemical and functional analysis of TIR domain containing protein from Brucella melitensis. Biochem. Biophys. Res. Commun. 397, 59-63. doi: 10.1016/j.bbrc.2010.0 5.056

Radhakrishnan, G. K., Yu, Q., Harms, J. S., and Splitter, G. A. (2009). Brucella TIR domain-containing protein mimics properties of the toll-like receptor adaptor protein TIRAP. J. Biol. Chem. 284, 9892-9898. doi: 10.1074/jbc.M8054 58200

Riley, L. K., and Robertson, D. C. (1984). Ingestion and intracellular survival of Brucella abortus in human and bovine polymorphonuclear leukocytes. Infect. Immun. 46, 224-230.

Robertson, G. T., and Roop, R. M. Jr. (1999). The Brucella abortus host factor I (HF-I) protein contributes to stress resistance during stationary phase and is a major determinant of virulence in mice. Mol. Microbiol. 34, 690-700. doi: 10.1046/j.1365-2958.1999.01629.x

Rolan, H. G., and Tsolis, R. M. (2007). Mice lacking components of adaptive immunity show increased Brucella abortus virB mutant colonization. Infect. Immun. 75, 2965-2973. doi: 10.1128/IAI.01896-06

Roop, R. M. II., Gaines, J. M., Anderson, E. S., Caswell, C. C., and Martin, D. W. (2009). Survival of the fittest: how Brucella strains adapt to their intracellular niche in the host. Med. Microbiol. Immunol. 198, 221-238. doi: 10.1007/s00430009-0123-8

Rossi, A. H., Farias, A., Fernandez, J. E., Bonomi, H. R., Goldbaum, F. A., and Berguer, P. M. (2015). Brucella spp. lumazine synthase induces a TLR4mediated protective response against B16 melanoma in mice. PLOS ONE 10:e0126827. doi: 10.1371/journal.pone.0126827

Roux, C. M., Rolan, H. G., Santos, R. L., Beremand, P. D., Thomas, T. L., Adams, L. G., et al. (2007). Brucella requires a functional Type IV secretion system to elicit innate immune responses in mice. Cell. Microbiol. 9, 1851-1869. doi: 10.1111/j.1462-5822.2007.00922.x

Salcedo, S. P., Marchesini, M. I., Lelouard, H., Fugier, E., Jolly, G., Balor, S., et al. (2008). Brucella control of dendritic cell maturation is dependent 
on the TIR-Containing protein btp1. PLoS Pathog 4:e40021. doi: 10.1371/journal.ppat.0040021

Schulte, L. N., Westermann, A. J., and Vogel, J. (2013). Differential activation and functional specialization of miR-146 and miR-155 in innate immune sensing. Nucleic Acids Res. 41, 542-553. doi: 10.1093/nar/gks1030

Scian, R., Barrionuevo, P., Rodriguez, A. M., Arriola Benitez, P. C., Garcia Samartino, C., Fossati, C. A., et al. (2013). Brucella abortus invasion of synoviocytes inhibits apoptosis and induces bone resorption through RANKL expression. Infect. Immun. 81, 1940-1951. doi: 10.1128/IAI.01 366-12

Smith, C. M., Wilson, N. S., Waithman, J., Villadangos, J. A., Carbone, F. R., Heath, W. R., et al. (2004). Cognate CD4(+) T cell licensing of dendritic cells in CD8(+) T cell immunity. Nat. Immunol. 5, 1143-1148. doi: 10.1038/ nil129

Smith, J. A., Khan, M., Magnani, D. D., Harms, J. S., Durward, M., Radhakrishnan, G. K., et al. (2013). Brucella induces an unfolded protein response via TcpB that supports intracellular replication in macrophages. PLoS Pathog 9:e1003785. doi: 10.1371/journal.ppat.1003785

Snyder, G. A., Deredge, D., Waldhuber, A., Fresquez, T., Wilkins, D. Z., Smith, P. T., et al. (2014). Crystal structures of the toll/interleukin-1 receptor (TIR) domains from the Brucella protein TcpB and host adaptor TIRAP reveal mechanisms of molecular mimicry. J. Biol. Chem. 289, 669-679. doi: 10.1074/jbc.M113.523407

Snyderman, R., Gewurz, H., and Mergenhagen, S. E. (1968). Interactions of the complement system with endotoxic lipopolysaccharide. Generation of a factor chemotactic for polymorphonuclear leukocytes. J. Exp. Med. 128, 259-275. doi: 10.1084/jem.128.2.259

Sola-Landa, A., Pizarro-Cerda, J., Grillo, M. J., Moreno, E., Moriyon, I., Blasco, J. M., et al. (1998). A two-component regulatory system playing a critical role in plant pathogens and endosymbionts is present in Brucella abortus and controls cell invasion and virulence. Mol. Microbiol. 29, 125-138. doi: 10.1046/j.1365-2958.1998.00913.x

Spera, J. M., Comerci, D. J., and Ugalde, J. E. (2014). Brucella alters the immune response in a prpA-dependent manner. Microb. Pathogenesis 67-68, 8-13. doi: 10.1016/j.micpath.2014.01.003

Spera, J. M., Herrmann, C. K., Roset, M. S., Comerci, D. J., and Ugalde, J. E. (2013). A Brucella virulence factor targets macrophages to trigger b-cell proliferation. J. Biol. Chem. 288, 20208-20216. doi: 10.1074/jbc.M113.453282

Spera, J. M., Ugalde, J. E., Mucci, J., Comerci, D. J., and Ugalde, R. A. (2006). A B lymphocyte mitogen is a Brucella abortus virulence factor required for persistent infection. Proc. Nat. Acad. Sci. U.S.A. 103, 16514-16519. doi: 10.1073/pnas.0603362103

Starr, T., Child, R., Wehrly, T. D., Hansen, B., Hwang, S., Lopez-Otin, C., et al. (2012). Selective subversion of autophagy complexes facilitates completion of the Brucella intracellular cycle. Cell Host Microbe 11, 33-45. doi: 10.1016/j.chom.2011.12.002

Starr, T., Ng, T. W., Wehrly, T. D., Knodler, L. A., and Celli, J. (2008). Brucella intracellular replication requires trafficking through the late endosomal/lysosomal compartment. Traffic 9, 678-694. doi: 10.1111/j.16000854.2008.00718.x

Taguchi, Y., Imaoka, K., Kataoka, M., Uda, A., Nakatsu, D., Horii-Okazaki, S., et al. (2015). Yip1A, a Novel Host Factor for the Activation of the IRE1 Pathway of the Unfolded Protein Response during Brucella Infection. PLoS Pathog. 11:e1004747. doi: 10.1371/journal.ppat.1004747
Tili, E., Michaille, J. J., Cimino, A., Costinean, S., Dumitru, C. D., Adair, B., et al. (2007). Modulation of miR-155 and miR-125b levels following lipopolysaccharide/TNF-alpha stimulation and their possible roles in regulating the response to endotoxin shock. J. Immunol. 179, 5082-5089. doi: 10.4049/jimmunol.179.8.5082

Velasquez, L. N., Delpino, M. V., Ibanez, A. E., Coria, L. M., Miraglia, M. C., Scian, R., et al. (2012). Brucella abortus induces apoptosis of human T lymphocytes. Microbes Infect. 14, 639-650. doi: 10.1016/j.micinf.2012.02.004

von Bargen, K., Gorvel, J. P., and Salcedo, S. P. (2012). Internal affairs: investigating the Brucella intracellular lifestyle. Fems Microb. Rev. 36, 533-562. doi: 10.1111/j.1574-6976.2012.00334.x

Wang, J., Tan, D. Y., Cai, Y. Y., Reinisch, K. M., Walz, T., and Ferro-Novick, S. (2014). A requirement for ER-derived COPII vesicles in phagophore initiation. Autophagy 10, 708-709. doi: 10.4161/auto.28103

Wang, Y., Ke, Y., Xu, J., Wang, L., Wang, T., Liang, H., et al. (2015). Identification of a Novel Small Non-Coding RNA Modulating the Intracellular Survival of Brucella melitensis. Front. Microbiol. 6:164. doi: 10.3389/fmicb.2015. 00164

Wang, Y. F., Chen, Z. L., Qiu, Y. F., Ke, Y. H., Xu, J., Yuan, X. T., et al. (2012). Identification of Brucella abortus virulence proteins that modulate the host immune response (vol 7, pg 29552, 2012). Bioengineered 3, 303-305. doi: 10.4161/bioe. 21005

Watarai, M., Makino, S., Fujii, Y., Okamoto, K., and Shirahata, T. (2002). Modulation of Brucella-induced macropinocytosis by lipid rafts mediates intracellular replication. Cell. Microbiol. 4, 341-355. doi: 10.1046/j.14625822.2002.00195.x

Weeks, J. N., Galindo, C. L., Drake, K. L., Adams, G. L., Garner, H. R., and Ficht, T. A. (2010). Brucella melitensis VjbR and C12-HSL regulons: contributions of the $\mathrm{N}$-dodecanoyl homoserine lactone signaling molecule and LuxR homologue VjbR to gene expression. BMC Microbiol. 10:167. doi: 10.1186/1471-2180-10167

Wei, P., Cui, G., Lu, Q., Yang, L., Guan, Z., Sun, W., et al. (2015). A20 promotes Brucella intracellular growth via inhibition of macrophage cell death and activation. Vet. Microbiol. 175, 50-57. doi: 10.1016/j.vetmic.2014.11.006

Whatmore, A. M., Perrett, L. L., and MacMillan, A. P. (2007). Characterisation of the genetic diversity of Brucella by multilocus sequencing. BMC Microbiol. 7:34. doi: 10.1186/1471-2180-7-34

Yang, Z. F., and Klionsky, D. J. (2010). Mammalian autophagy: core molecular machinery and signaling regulation. Curr. Opin. Cell Biol. 22, 124-131. doi: 10.1016/j.ceb.2009.11.014

Zheng, K., Chen, D. S., Wu, Y. Q., Xu, X. J., Zhang, H., Chen, C. F., et al. (2012). MicroRNA expression profile in RAW264.7 cells in response to Brucella melitensis infection. Int. J. Biol. Sci. 8, 1013-1022. doi: 10.7150/ijbs.3836

Conflict of Interest Statement: The authors declare that the research was conducted in the absence of any commercial or financial relationships that could be construed as a potential conflict of interest.

Copyright (C) 2016 Ahmed, Zheng and Liu. This is an open-access article distributed under the terms of the Creative Commons Attribution License (CC BY). The use, distribution or reproduction in other forums is permitted, provided the original author(s) or licensor are credited and that the original publication in this journal is cited, in accordance with accepted academic practice. No use, distribution or reproduction is permitted which does not comply with these terms. 